objectification as moderators. International Journal of Eating Discorders. Retrieved from: https://doi.org/10.1002/eat.23393

3. Bourne, Michael. «Publishing During a Pandemic: THE EFFECTS OF COVID-19 ON THE BUSINESS OF BOOKS». Poets \& Writers Magazine, vol. 48, no. 4, 2020, p. 75+. Gale Academic OneFile.

4. Krystofydes N. Teoryya hrafov. Alhorytmycheskyy podkhod M.: Myr, 1978, 432 s.

\title{
ALGORITHM OF CREATING VIRTUAL TOURS
}

\section{Valeriia Sanchenko ${ }^{1}$}

DOI: https://doi.org/10.30525/978-9934-26-002-5-54

Today, virtual tours are very popular, which due to their interactivity has the ability to fill the tour with a variety of information. From text aids, animated illustrations, graphics, background music or an audio route guide to the use of maps and geolocations. Virtual reality mapping is of interest to many areas of our lives. The entertainment and gaming industry was one of the first to make extensive use of virtual reality. Real estate, advertising and marketing, tourism and many other areas are interested in the development of virtual tours. A virtual tour is a way to realistically display the surrounding space on a flat screen. It is a powerful and effective advertising and marketing tool. Also it allows you to get complete information about a service or product.

Virtual tour is one of the most effective and convincing ways to present information at the moment, as it allows you to make exciting virtual tours and create a complete illusion of the viewer's presence.

Creating a quality product is possible through the use of modern equipment and software, qualified personnel, automation of production processes.

At first, the general technology of creating virtual tours was defined. Virtual tours are based on several 3D panoramas connected by navigation buttons. To create a tour, you must first determine the specification of the object. It is necessary to deal with a number of issues, namely: what tour should be; what it is set up for and what topics; filling; how many locations should be; number of frames of panoramas. After the technical task is developed, the necessary multimedia information is selected and processed, such as text, animation, audio, video content. In parallel, the basic objects are

\footnotetext{
${ }^{1}$ National Technical University of Ukraine «Igor Sikorsky Kyiv Polytechnic Institute», Ukraine
} 
created: photographing the panorama at the desired angle of rotation and the specified number of frames. Then goes processing of photos and creating panoramas. After that, navigation is created and multimedia information is entered into a virtual tour. Virtual tour testing and adjustments. Then there is an agreement with the customer and completion of the virtual tour, final edits.

Creating virtual tours is gradual and has many stages. The process is performed according to the appropriate algorithm. The task of the work was to develop an algorithm for creating a virtual tour.

As a result of the performed work, an algorithm for creating a virtual tour was developed (Figure), Which describes all stages of design, development of elements, creation of panoramas, processing of material and introduction of elements to the final product.

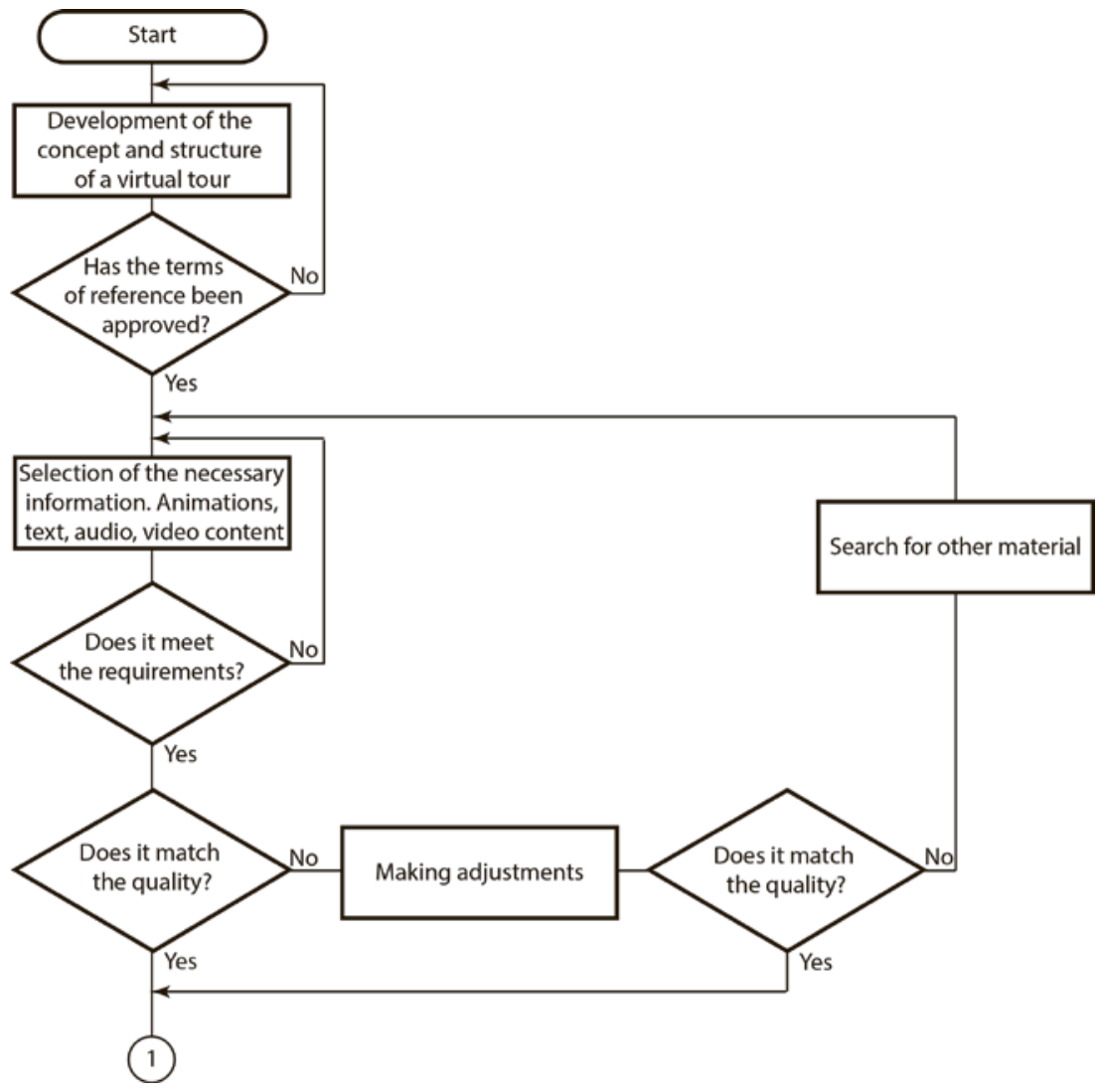




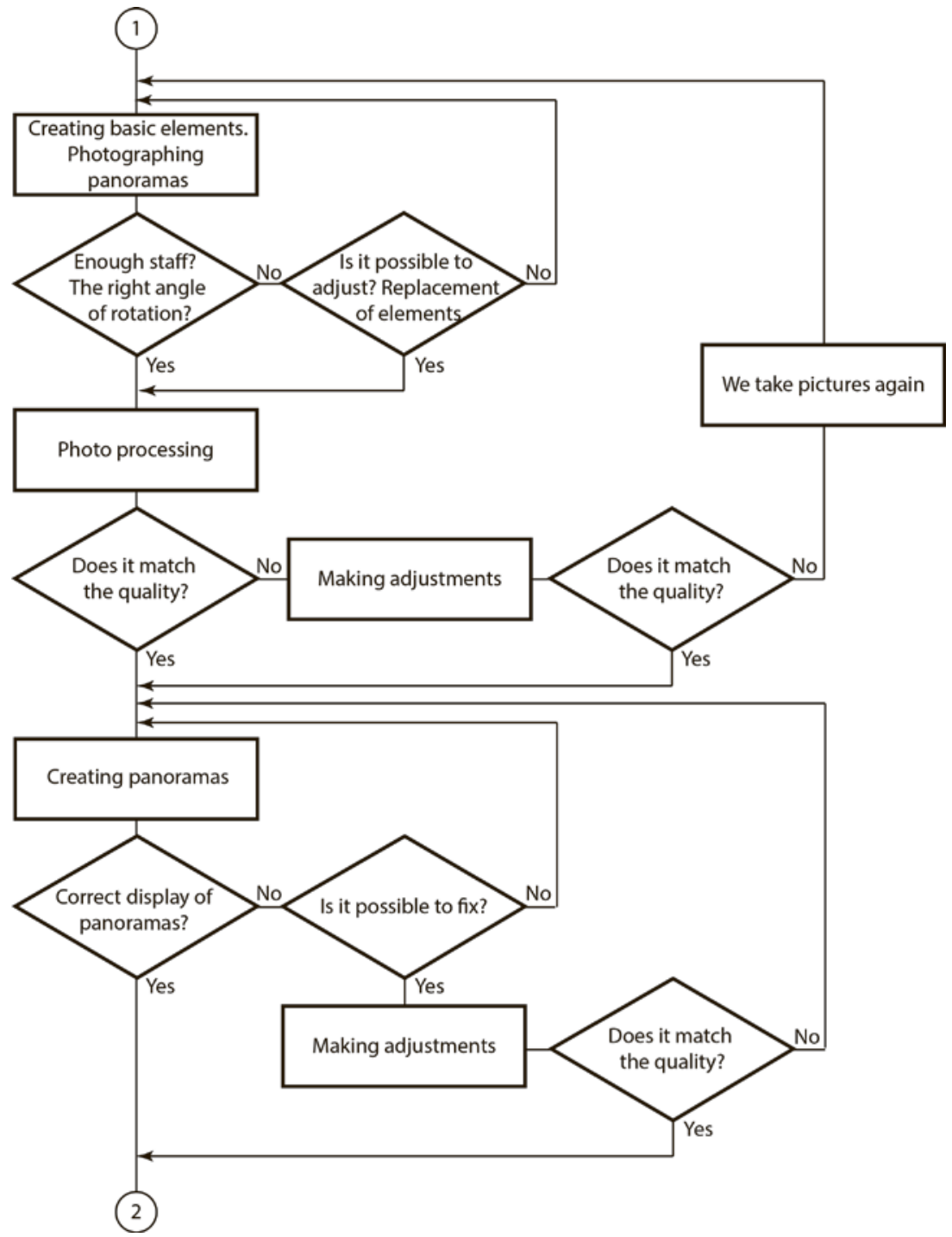




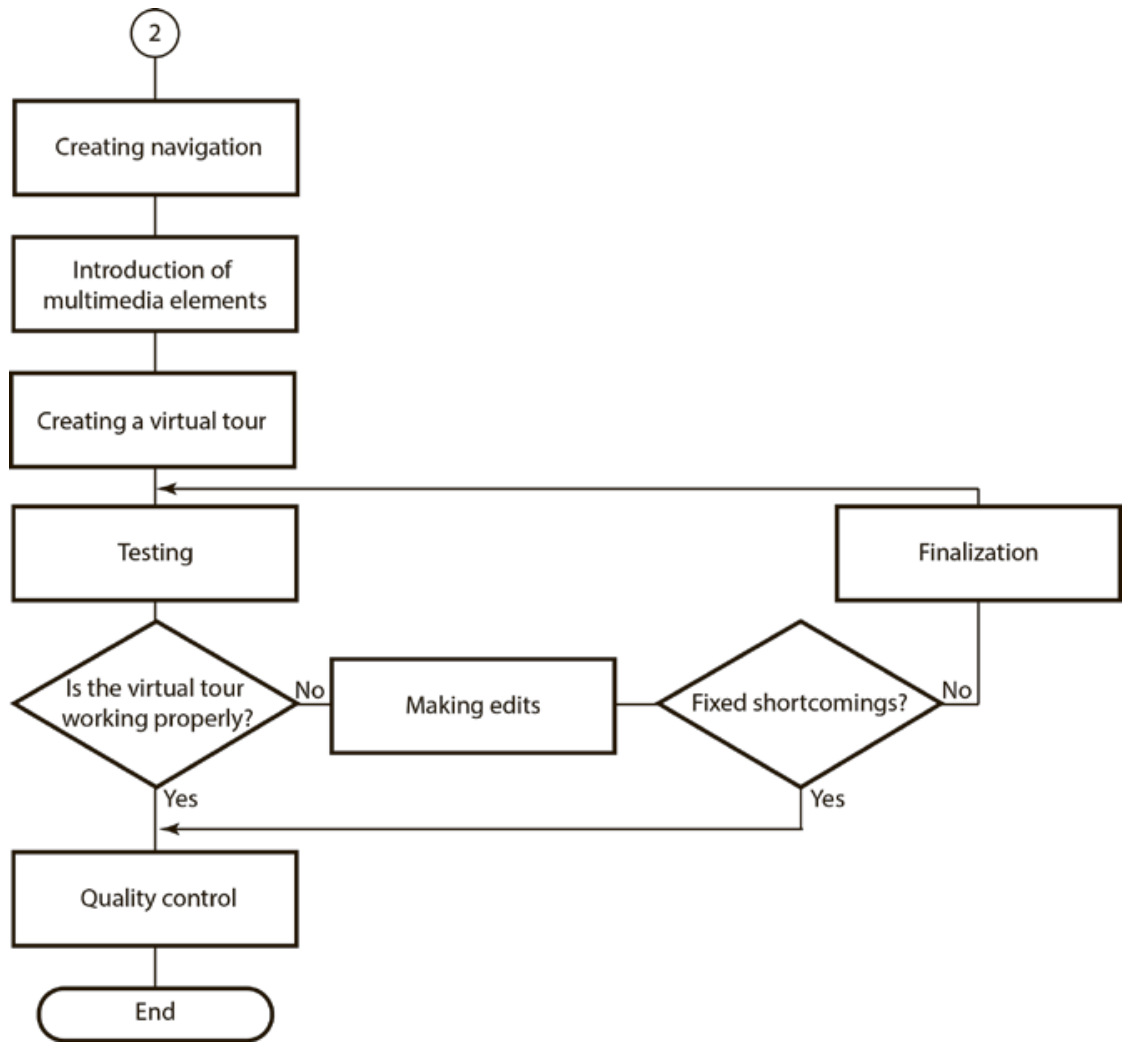

\section{References:}

1. Shlyakhtina, S. (2006). Pro tekhnologhiju stvorennja virtualjnykh turiv [About the technology of creating virtual tours]. Retrieved November 18, 2020, from: https://compress.ru/article.aspx?id=15669 